\title{
Spectrochemical Analysis of Bronze by a Porous Electrode Method
}

\author{
Bourdon F. Scribner and John C. Ballinger
}

\begin{abstract}
A modification of Feldman's porous electrode method is described for the spectrochemical analysis of bronze ( $3 \mathrm{Sn}, 3 \mathrm{Zn}, 2 \mathrm{~Pb}, 2 \mathrm{Ni}, 90 \mathrm{Cu}$ ). A 1-gram sample of bronze drillings is dissolved by the addition of 4 milliliters of hydrochloric acid and 16 milliliters of nitric acid, and after dilution to 40 milliliters with water, the solution is transferred to the hollow electrode for spark excitation. The analysis is made with reference to standard solutions prepared in a similar manner. Studies of the effect of electrode shape on the reproducibility of excitation led to the adoption of a porous electrode having a tip in the shape of a truncated cone. With this electrode the precision was greater by a factor of 1.2 to 2.1 over that obtained with a flat-tipped electrode. The precision of the method, determined as the coefficient of variation of a group of duplicate runs on 50 samples, ranged from 1.6 percent for nickel to 4.3 percent for lead. On the average, the results of routine spectrochemical determinations agree with the results of chemical determinations on the same samples to within \pm 5 percent.
\end{abstract}

\section{Introduction}

In spectrographic analyses of low-tin statuary bronze ( $3 \mathrm{Sn}, 3 \mathrm{Zn}, 2 \mathrm{~Pb}, 2 \mathrm{Ni}, 90 \mathrm{Cu}$ ) by methods involving the direct sparking of the metal, certain unaccountable variations from the results of chemical analyses were observed. Although a group of samples prepared over a short period of time by a single manufacturer was found to give results entirely consistent within themselves, comparison of this group of samples with a group made at a later date, or by another manufacturer, revealed variations that could not be traced to the analytical method or technique. Others who have studied the analysis of copper alloys by direct spark methods have encountered similar difficulties and have placed considerable emphasis on preparation of the sample. It has been found necessary to exercise rigid control over the temperature of the melt, the rate of cooling, and the form of the sample [1]. ${ }^{1}$

If samples from many sources were to be analyzed, it appeared advisable to adopt a method that would erase any effects of differences in metallurgical processing. It was also important to preserve the analytical speed made possible by the spectrochemical method. A procedure for obtaining physically identical electrodes by remelting the bronze under carefully controlled conditions is described by Palmer, Irwin, and Fogg [2]. In the search for a more rapid and flexible method, we considered the practicability of applying a solution technique. An excellent review of existing solution methods adaptable to spark excitation may be found in the paper by Feldman [3]. The method developed by him and described in his paper involved the use of a porous cup electrode. The possibility of applying this method to the anal$y$ sis of bronze was tested with encouraging results.

Attention was then directed toward investigating details of the procedure to obtain maximum speed and precision with sufficient sensitivity. Several electrode shapes and sizes were investigated, as well as a variety of sparking conditions, with the result

\footnotetext{
1 Figures in brackets indicate the literature references at the end of this paper.
}

that an improved form of electrode was designed. Water-cooled copper electrode holders were found to be effective in preventing boiling of the solution as the spark energy was increased. Graphite bushings in the electrode holder were adopted to retard acid attack. Also, special sampling and dissolution methods were developed to give speed and facility to preparation of the solution. The standards consisted both of samples analyzed chemically and samples synthesized in acid solution by dissolving pure metals in the proper proportions. Calculating scales served to expedite and simplify the conversion of microphotometer readings to concentration values.

\section{Preparation of Solutions}

\subsection{Sample Solutions}

The bronze samples are prepared as drillings or millings to obtain material in convenient form for weighing and dissolution. In order to speed up the drilling operation a drill press is fitted with the jig assembly shown in figure 1 . The test sample, which is generally in the form of a bar $1 / 2$ by $1 / 2$ by 4 in., is cleaned on two opposite long faces with a belt sander and is inserted in the jig. A clean, glass vial, fastened in the threaded opening on the underside of the jig, serves to collect the drillings. Sufficient material for test is obtained from one $1 / 4$-in. hole drilled through the middle of the bar from one cleaned surface to the other.

A $1.0-\mathrm{g}$ portion of the sample is transferred to a 125-ml Erlenmeyer flask, to which is added $4 \mathrm{ml}$ of hydrochloric acid (sp gr 1.19) followed by the addition of $16 \mathrm{ml}$ of nitric acid ( $\mathrm{sp} \mathrm{gr} 1.42$ ). When the reaction has ceased, $20 \mathrm{ml}$ of water is added. Care is taken that dissolution is complete after addition of the water; this may be accelerated by gentle warming. Three self-leveling burettes serve for rapid dispensing of the acids and water. Because of the toxicity of the acid fumes, adequate ventilation must be maintained during both the preparation and storage of the solutions. 


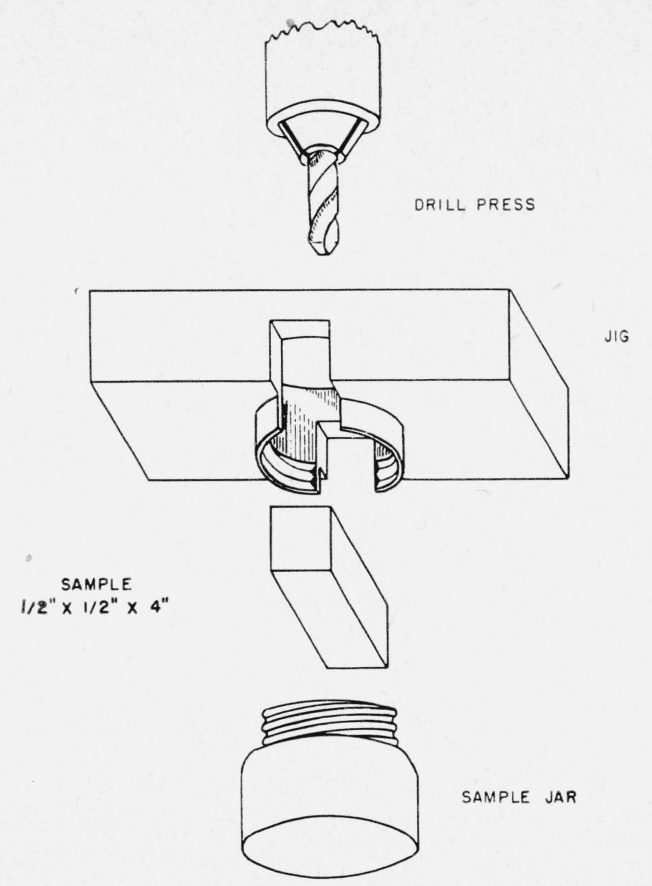

Figure 1. Assembly for drilling and collecting sample.

\subsection{Standard Solutions}

Chemically analyzed bronze samples serve as standards if selected so that concentrations of $\mathrm{Pb}$, $\mathrm{Ni}, \mathrm{Sn}$, and $\mathrm{Zn}$ cover the desired ranges, and the concentration of copper is within 3 percent of that of the analytical samples. The latter condition is imposed to avoid the necessity of correcting for differences in the concentration of the internal standard copper between standards and analytical samples. Solutions of the metal standards are prepared in the manner described for the analytical samples. Synthetic standards may be prepared by dissolving pure metal constituents, provided that the resulting solutions match those of the analytical samples with respect to total metal concentration, concentration of copper, and concentration of acids. For the analysis of bronze in which copper varies from 89 to 91 percent, the copper may be held within this range by preparing solutions in which the compositions of the dissolved metals correspond to those of the alloys given in table 1.

The individual standard solutions of nickel, lead, and zinc may be prepared conveniently by dissolving the metals in a minimum of dilute nitric acid (1:1) and diluting with water to obtain a concentration of $0.01 \mathrm{~g}$ of metal per milliliter. For tin, dilute hydrochloric acid (1:1) is used and a solution of the same concentration is prepared. The set of bronze standard solutions is prepared by dissolving the required amount of copper in aqua regia $(4 \mathrm{ml}$ of hydrochloric acid plus $16 \mathrm{ml}$ of nitric acid), and then adding water and metal solutions in the proper proportions.

Comparative testing of synthetically prepared standards and carefully analyzed chemical standards

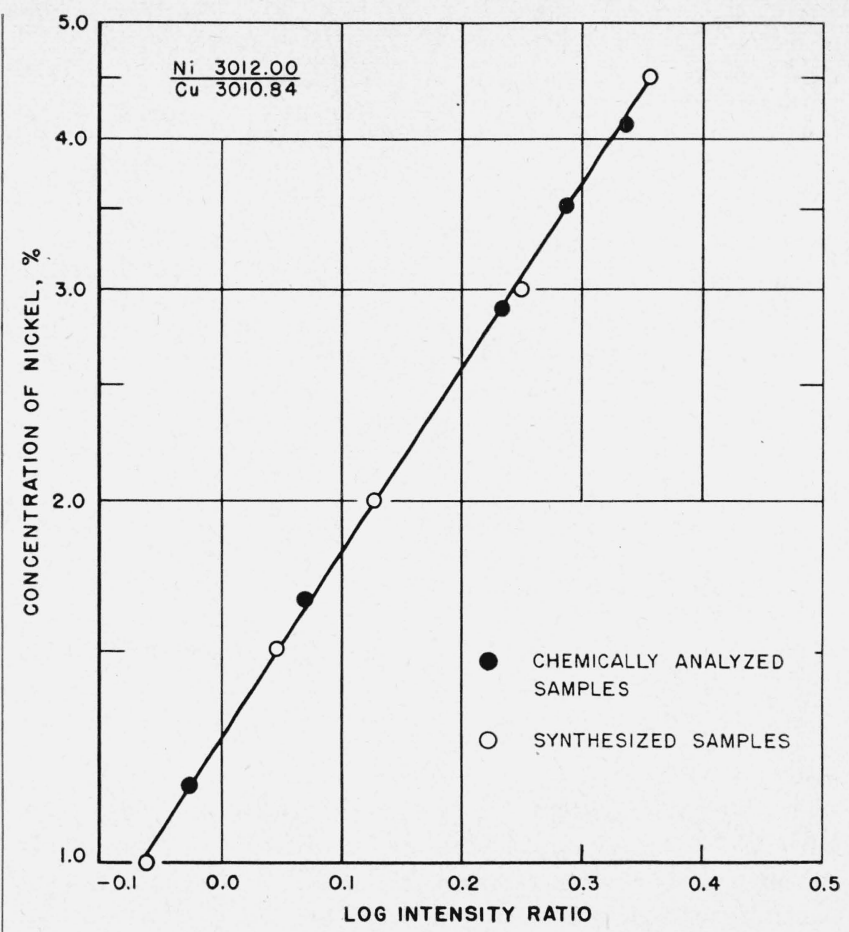

Figure 2. Analytical curve for nickel.

TABLE 1. Compositions of alloys corresponding to standards prepared in solution

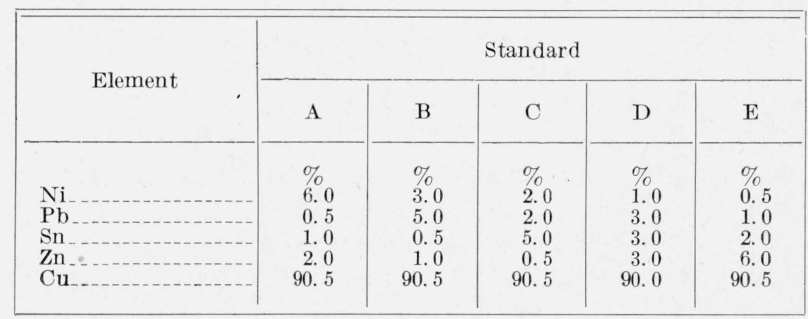

has indicated good agreement, as is shown on the analytical curve for nickel, figure 2 .

\section{Spark Excitation}

\subsection{Electrode System}

The solution electrode, figure 3 , is prepared from graphite rods of high purity, $1 / 4 \mathrm{in}$. in diameter. Its form, with the exception of a truncated tip, is similar to that described by Feldman [3]. The upper (porous cup) electrode is $1 \frac{3}{8}$ in. long with a $1 \frac{1}{8}$-in. hole drilled along its axis from one end to within 0.05 $( \pm 0.008)$ in., or $1.3( \pm 0.2) \mathrm{mm}$ of the other end. A standard $1 / 8$-in. twist drill is employed but, for ease in drilling, the grooves of the drill are ground wider to provide more space for carrying the chips away from the head of the drill. The sparking end of the electrode is beveled on the edge to an angle of $45^{\circ}$, resulting in a truncated cone with a tip diameter of $1 / 8$ in. Tests of various electrode shapes showed a marked improvement in the precision of 


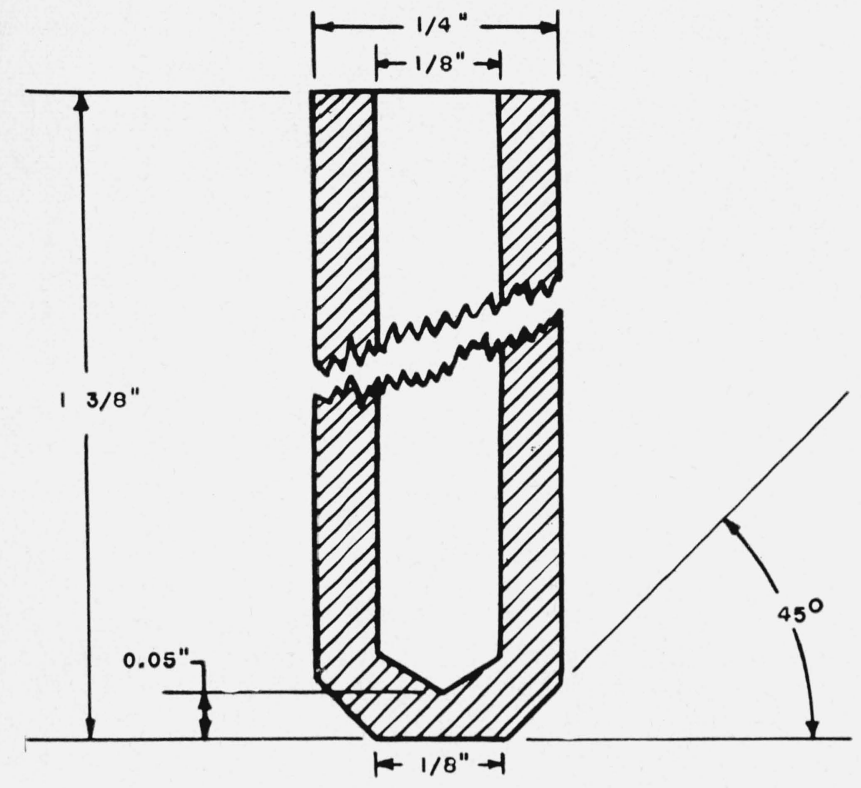

Figure 3. Electrode for sparking the solution.

results as the tip of the electrode was reduced in diameter. An electrode with a tip $1 \frac{1}{8}$ in. in diameter was adopted with gains in precision amounting to a factor of 1.2 to 2.1 , as shown in table 2 .

TABLE 2. Repeatability tests of two electrode tips

\begin{tabular}{|c|c|c|c|c|}
\hline \multirow[b]{2}{*}{ Element } & \multirow[b]{2}{*}{$\begin{array}{l}\text { Concentra- } \\
\text { tion }\end{array}$} & \multicolumn{2}{|c|}{ Coefficient of variation a } & \multirow[b]{2}{*}{$\begin{array}{l}\text { Number of } \\
\text { observations }\end{array}$} \\
\hline & & $\begin{array}{l}\text { Truncated } \\
\text { cone, tip di- } \\
\text { ameter 1,8 in. }\end{array}$ & $\begin{array}{l}\text { Flat end, tip } \\
\text { diameter } \\
1 / 4 \text { in. }\end{array}$ & \\
\hline $\begin{array}{l}\mathrm{Ni} \\
\mathrm{Pb} \\
\mathrm{Sn} \\
\mathrm{Zn}\end{array}$ & $\begin{array}{l}\% \\
1.9 \\
2.5 \\
3.5 \\
3.5\end{array}$ & $\begin{array}{l}\% \\
1.4 \\
2.3 \\
2.8 \\
1.8\end{array}$ & $\begin{array}{l}\% \\
1.7 \\
4.4 \\
5.8 \\
2.7\end{array}$ & $\begin{array}{l}20 \\
20 \\
20 \\
20\end{array}$ \\
\hline
\end{tabular}

a $\nu=\frac{100 \sigma}{C}=\frac{100}{C} \sqrt{\frac{\Sigma d^{2}}{n-1}}$, where $\nu$ is the coefficient of variation; $\sigma$ the standard deviation: $C$ the concentration in percent; $d$ the difference of a determination from the mean; $n$ the number of determinations.

A pipette with an elongated tip $1 \frac{1 / 2}{2}$ in. long and less than $1 / 8$-in. outside diameter is used for filling the porous cup electrode in the manner illustrated by Feldman [3]. The tip of the pipette should touch the bottom of the electrode cavity, as the solution is expelled, to prevent the formation of bubbles within the electrode. The electrode is filled to the top $(0.3 \mathrm{ml})$ immediately before sparking. The lower graphite electrode, $1 / 14 \mathrm{in}$. in diameter, is shaped at the tip to a $120^{\circ}$ cone and is clamped vertically in opposition to the upper electrode. The electrodes, separated by a $3-\mathrm{mm}$ gap, are held in 1/2-in. split graphite bushings, which in turn are held in watercooled copper clamps [4]. The water-cooled clamps were found effective in preventing boiling of the solution.

\subsection{Excitation Conditions}

The spark excitation conditions have an important effect upon both the sensitivity and repeatability of

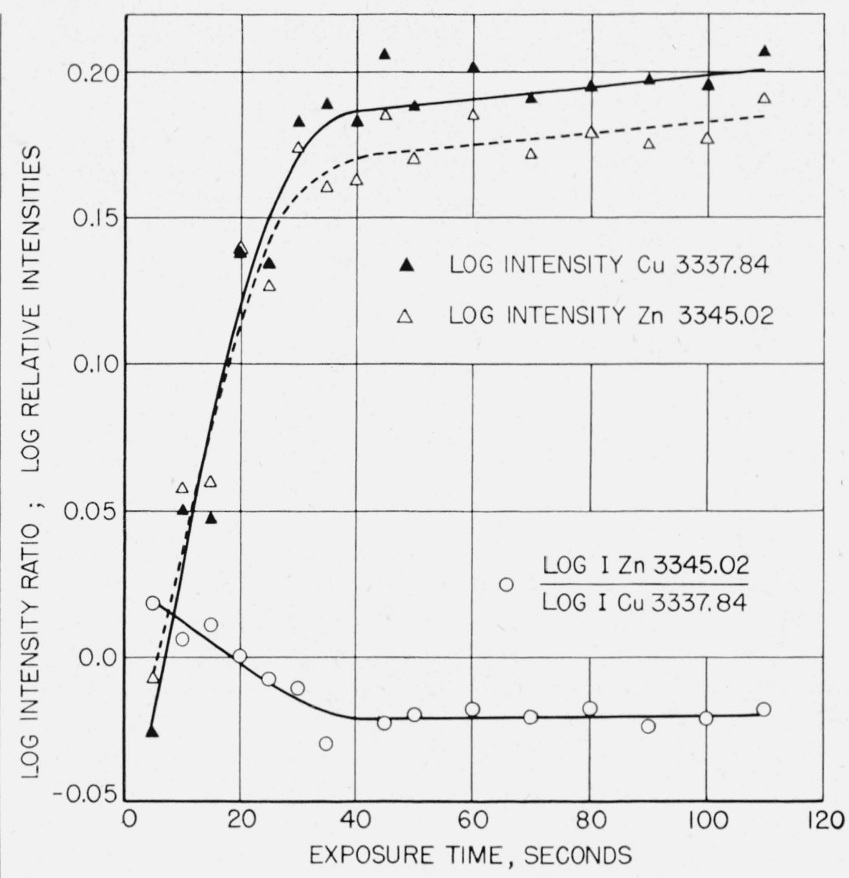

FIGURE 4. Change of spectral line intensities with time of sparking.

this method. A high-energy spark is desirable in that it provides high sensitivity. However, when the energy is raised considerably, the heat generated cannot be dissipated rapidly enough to prevent boiling of the solution within the electrode. This results in an erratic, irreproducible spark. A compromise of conditions has therefore been selected. Sensitivity is also affected by the inductance of the circuit, any considerable increase beyond $25 \mu \mathrm{h}$ producing a high background intensity with a corresponding decrease in sensitivity. An Applied Research Laboratories' high-voltage spark unit was employed, although any unit capable of being adjusted to obtain a low-energy spark should be satisfactory. The settings used with this unit are as follows: Power setting, $2 / 3 \mathrm{kva}$; capacitance, 0.0073 $\mu \mathrm{f}$; inductance, $25 \mu \mathrm{h}$; interrupter adjustment, set for a low-energy spark (26 volts on the indicating instrument furnished with the unit).

Under these conditions the spectrum assumes a fairly stable intensity level after the first 35 seconds and maintains it for well over 2 minutes, as shown in figure 4. On the basis of these observations it would appear preferable to allow a period of 35 seconds before making the exposure. However, in practice a shorter period was allowed in order to reduce the total time. A presparking period of 10 sec. and an exposure of 110 seconds were adopted.

\section{Analytical Procedure}

\subsection{Spectrographic Procedure}

A conventional large Littrow quartz spectrograph and illuminating system are employed to photograph the range 2650 to $3400 \mathrm{~A}[5]$. With a lens $\left(f_{d}=34\right.$ 
$\mathrm{cm}$ ) at the slit, the arrangement is such that the resulting spectrum represents radiant energy from all parts of the spark. A step sector or other variation of exposure is not needed for this analysis. In routine work, the spectrum of each sample is photographed in duplicate, but on separate plates for higher accuracy. On each plate one exposure is made for each of 18 samples and 2 standards. In addition, an exposure of the iron spark spectrum is made on the plate for calibrating the emulsion with the following exposure conditions: Power setting, $4 / 3$ kva; capacitance, $0.014 \mu \mathrm{f}$; inductance (none added), $3 \mu \mathrm{h}$; interrupter adjustment, set for spark of moderate energy (40 volts on the indicating instrument furnished with the unit); electrode form, two electrodes of commercially pure rods $1 / 4$ in. in diameter each tipped with a $150^{\circ}$ cone; electrode separation, $3 \mathrm{~mm}$; exposure time, 30 sec.

The copper spectrum obtained displays a sufficient number of lines of varying intensities in the range from 2650 to 3400 A to eliminate the need for a stepped sector or other variation of exposure. Analytical line pairs used in this method are listed in table 3 . The only interference observed was that caused by $\mathrm{Na} 3302.32$ A with Zn 3302.59 A. This was attributed to contamination of the sample during the sampling or dissolution procedures and was eliminated entirely when adequate precautions were taken. Good ventilation of the spark stand during the sparking procedure was found advisable to prevent serious corrosive attack by the acid fumes on neighboring apparatus and toxic effects on the operator.

TABLE 3. Analytical Line pairs

\begin{tabular}{|c|c|c|c|c|}
\hline $\begin{array}{l}\text { Element to } \\
\text { be deter- } \\
\text { mined }\end{array}$ & $\begin{array}{l}\text { Wavelength of } \\
\text { element line a }\end{array}$ & $\begin{array}{l}\text { Wavelength of } \\
\text { copper line }{ }^{\text {a }}\end{array}$ & $\begin{array}{l}\text { Concentration } \\
\text { range }\end{array}$ & $\begin{array}{l}\text { Concen- } \\
\text { tration } \\
\text { index b }\end{array}$ \\
\hline $\mathrm{Ni}_{2}$ & $\begin{array}{l}A \\
3057.64 \\
3012.00 \\
3050.82\end{array}$ & $\begin{array}{l}A \\
3063.42 \\
3010.84 \\
3073.80\end{array}$ & $\begin{array}{c}\% \\
1.0 \text { to } 5.0 \\
0.5 \text { to } 2.5 \\
.5 \text { to } 0.7\end{array}$ & $\begin{array}{r}\%^{2.1} \\
1.3 \\
0.3\end{array}$ \\
\hline $\mathrm{Pb}$ & $\begin{array}{l}2833.07 \\
3683.47\end{array}$ & $\begin{array}{l}3010.84 \\
3684.67\end{array}$ & $\begin{array}{l}.5 \text { to } 5.0 \\
.5 \text { to } 1.2\end{array}$ & $\begin{array}{l}2.9 \\
0.4\end{array}$ \\
\hline $\mathrm{Sn}_{-}$ & $\begin{array}{l}3009.15 \\
3175.05 \\
3175.05\end{array}$ & $\begin{array}{l}3010.84 \\
3194.10 \\
3169.68\end{array}$ & $\begin{array}{l}1.5 \text { to } 5.0 \\
0.6 \text { to } 2.5 \\
.5 \text { to } 1.0\end{array}$ & $\begin{array}{l}3.0 \\
1.3 \\
0.4\end{array}$ \\
\hline $\mathrm{Zn}_{\ldots}$ & $\begin{array}{l}3302.59 \\
3345.02 \\
3345.02\end{array}$ & $\begin{array}{l}3279.82 \\
3337.84 \\
3349.29\end{array}$ & $\begin{array}{l}2.5 \text { to } 5.5 \\
0.7 \text { to } 3.0 \\
.5 \text { to } 1.5\end{array}$ & $\begin{array}{l}4.0 \\
1.7 \\
0.6\end{array}$ \\
\hline
\end{tabular}

a All wavelengths are from neutral atoms.

b The concentration index is the concentration at which the intensity ratio is unity.

\subsection{Photometry}

The emulsion is calibrated by photometric measurement of the iron spark exposure for the selected group of iron lines listed in table 4 , the relative intensities of which were determined by a primary method, using a step sector. ${ }^{2}$ These lines are used in preparing a plate calibration curve as outlined by Vincent and Sawyer [6]. Transmittance measurements of analytical line pairs and lines of the cali-

2 The calibration procedure, established by C. H. Corliss, is common to several analytical methods employed in this laboratory. bration spectrum are made with a projection microphotometer. Analytical line pairs appropriate to the concentration ranges encountered are selected from the list in table 3 . The transmittances of the analytical lines and the internal standard lines are converted to $\log$ intensity ratios by means of the plate calibration curve. This procedure, carried through for standard samples, serves to establish an analytical curve relating $\log$ intensity ratio and log concentration for each line pair. A typical analytical curve, that for nickel, is illustrated in figure 2. $\log$ intensity ratios of analytical determinations may then be converted to concentrations by reference to the appropriate analytical curve. The average of two determinations, each made on a separate plate, and corrected by a control standard in duplicate on each plate, is reported for each element. In view of the fact that the principal alloying constituents of the bronze other than copper are determined directly by the method, a reasonably accurate value of the copper concentration is obtained by subtracting the sum of the concentrations of tin, zinc, lead, and nickel from 100.

TABLE 4. Iron wavelengths (Fe II) for emulsion calibration

\begin{tabular}{|c|c|c|c|}
\hline \multicolumn{4}{|c|}{ Angstroms } \\
\hline 2770.51 & 2811.27 & 2875.35 & 2892.83 \\
\hline 2774.69 & 2827.43 & 2876.80 & 2897.26 \\
\hline 2793.89 & 2837.30 & 2879.24 & 2904.38 \\
\hline 2799. 29 & 2861.19 & จ 2880.8 & 2910.76 \\
\hline 2805. 79 & 2864.97 & 2885. 93 & 2934.49 \\
\hline
\end{tabular}

s Double line.

When samples are to be analyzed on a routine basis, the procedure is simplified by the use of analytical scales or of both analytical and calibration scales. The scales are prepared from the established analytical and calibration curves by projecting the curve to its intensity axis. The scales are then used in the manner described by Churchill [7] for the Dunn-Lowry calculator.

\section{Discussion}

\subsection{Precision and Accuracy}

Calculations of the precision of the method were made in two ways, first, by comparing a group of determinations on a single sample made under identical conditions, and second, by comparing duplicate determinations made on a large number of samples. In the first case a single solution was used in making all of the determinations, and care was taken to maintain the observing conditions constant. Coefficients of variation (defined in table 2) were computed for each plate (20 determinations) and the results averaged to give the values shown in table 5 .

In the second case actual routine test data were used involving 50 samples, where two exposures were made each on a separate plate. The values for coefficient of variation were calculated for the pairs of determinations with the results shown in table 6 . As one would expect, the coefficients of variation 
TABLE 5. Results of repeatability tests on a single sample

\begin{tabular}{|c|c|c|c|}
\hline Element & Concentration & $\begin{array}{c}\text { Coefficient of } \\
\text { variation a }\end{array}$ & $\begin{array}{c}\text { Number of ob- } \\
\text { servations b }\end{array}$ \\
\cline { 1 - 2 } & $\%$ & $\%$ & \\
\cline { 1 - 2 } & 1.9 & 1.9 & 100 \\
$\mathrm{Nb}$ & 2.5 & 2.8 & 100 \\
$\mathrm{Sn}$ & 3.5 & 3.9 & 100 \\
$\mathrm{Zn}$ & 3.5 & 1.8 & 80 \\
\hline
\end{tabular}

s See footnote a, table 2

b Treated in groups of 20 and the results averaged.

are larger here than in the first case and may be expected to represent a more realistic measure of the precision of the method. It is of interest to note the convenience of calculating precision from routine analytical data, thus obviating the necessity of making a large number of runs on a single sample under the somewhat improbable restriction of "constant conditions." However, the method of employing pairs of determinations is a reliable measure of the precision of the method only when the single determinations can be considered independent, that is, observed on different plates and preferably on different days.

The precision found for nickel is considerably better than that for lead, tin, and zinc. This is probably the result of a combination of factors that may include the close match between Ni $3012.00 \mathrm{~A}$ and $\mathrm{CuI} 3010.84 \mathrm{~A}$ in wavelength and excitation energy, as well as a close similarity in the physical properties of nickel and copper and their salts.

TABLE 6. Results of repeatability tests based on duplicate routine determinations made on 50 samples

\begin{tabular}{|c|c|c|c|}
\hline Element & $\begin{array}{l}\text { A verage con- } \\
\text { centration }\end{array}$ & $\begin{array}{l}\text { Coefficient of } \\
\text { variation }{ }^{\mathrm{a}}\end{array}$ & $\begin{array}{l}\text { Number of pairs } \\
\text { of observations }\end{array}$ \\
\hline $\begin{array}{l}\mathrm{Ni} \\
\mathrm{Pb} \\
\mathrm{Sn} \\
\mathrm{Zn}\end{array}$ & $\begin{array}{l}1.6 \\
2.3 \\
3.6 \\
3.2\end{array}$ & $\begin{array}{l}\% \\
1.6 \\
4.3 \\
4.2 \\
2.4\end{array}$ & $\begin{array}{l}50 \\
50 \\
50 \\
50\end{array}$ \\
\hline
\end{tabular}

a $\nu=\frac{100 \sigma}{C}=\frac{100}{C} \sqrt{\frac{\Sigma D^{2}}{2 p}}$, where $\nu$ is the coefficient of variation; $\sigma$ the standard deviation; $C$ the average concentration in percent; $D$ the difference between duplicate runs; $p$ the number of pairs of observations.

An expression for the accuracy of this method may be obtained by comparing the spectrochemical with chemical results. ${ }^{3}$ The differences between the averages of two sets of results for each element are given in column 4 of table 7 . The differences were found not to be significant, indicating that a bias was not observed. The average differences between determinations by the two methods, calculated without regard to sign, are given in column 5 of table 7 ; these give a measure of the expected random differences between determinations by the two methods. The differences, of course, include any errors in chemical analysis as well as those in the spectrographic determination. It is significant that the determinations of copper, made by

${ }^{3}$ The chemical analyses were made by R. K. Bell, E. E. Maczkowske, and K. M. Sappenfield of the Bureau's Analytical Chemistry Section. In the chemical method $\mathrm{Cu}, \mathrm{Sn}, \mathrm{Pb}$, and $\mathrm{Ni}$ are determined directly, and $\mathrm{Zn}$ is determined by difference. difference in the spectrographic method, show good agreement with the chemical determinations that were made directly by electrodeposition.

\subsection{Advantages and Limitations}

This method is particularly advantageous for the analysis of samples for which the metallurgical preparation, size, or shape cannot be controlled sufficiently well to permit application of a selfelectrode method. It is useful also in the absence of bronze metal standards covering the required concentration ranges. Because of continuous supply of sample solution to the electrode tip, there is negligible intensity variation after the first 25 or 30 sec of exposure (fig. 4); consequently the time of exposure may be changed considerably without appreciable effect on the intensity ratios. Furthermore, the intensity ratios are not critically affected by variations (up to a factor of 2 ) in the concentration of the sample in solution.

TABLE 7. Comparison of chemical and spectrochemical results

\begin{tabular}{|c|c|c|c|c|c|}
\hline Element & $\begin{array}{l}\text { Average of } \\
\text { chemical } \\
\text { determina- } \\
\text { tions }\end{array}$ & $\begin{array}{l}\text { A verage of } \\
\text { spectro- } \\
\text { chemical } \\
\text { determina- } \\
\text { tions }\end{array}$ & $\begin{array}{l}\text { Difference } \\
\text { between } \\
\text { averages }\end{array}$ & $\begin{array}{c}\text { Average } \\
\text { absolute } \\
\text { difference } \\
\text { between } \\
\text { determina- } \\
\text { tions }\end{array}$ & $\begin{array}{l}\text { Number } \\
\text { of } \\
\text { determina- } \\
\text { tions }\end{array}$ \\
\hline $\begin{array}{l}\mathrm{Ni} \\
\mathrm{Pb} \\
\mathrm{Sn} \\
\mathrm{Zn} \\
\mathrm{Cu}\end{array}$ & $\begin{array}{r}\% \\
1.55 \\
2.46 \\
3.43 \\
\mathrm{a} 2.65 \\
89.84\end{array}$ & $\begin{array}{r}\% \\
1.55 \\
2.41 \\
3.47 \\
2.73 \\
\text { a } 89.81\end{array}$ & $\begin{array}{r}\% \\
0.0 \\
+.05 \\
-.04 \\
-.08 \\
+.03\end{array}$ & $\begin{array}{r}\% \\
0.04 \\
.12 \\
.14 \\
.12 \\
.18\end{array}$ & $\begin{array}{l}50 \\
50 \\
50 \\
50 \\
50\end{array}$ \\
\hline
\end{tabular}

a Determined by difference.

The speed of the method is obviously less than that for methods using spark excitation of metal electrodes. However, in routine analyses one operator can maintain a rate of 50 samples analyzed per week, which is a time requirement of a little less than 10 man-minutes per determination (each determination being the average of two runs). An appreciable gain in the precision of analytical results is observed (table 2) for the truncated-tip electrode of our design when compared with Feldman's flat-tip electrode [3], both electrodes being tested with the same solutions of bronze. The accuracy of the method is sufficient for control testing at the concentration levels encountered, but if the method were to be extended to concentrations higher than 5 percent for the elements determined directly, the accuracy might be insufficient for close control. Limitations in the method are encountered in extending the concentration ranges for analyses beyond those given in table 3 . To extend the lower limits would involve either excessively long exposures or increasing the metal-to-acid ratio. The latter may be feasible, provided the sample can be dissolved completely. Similarly, the extension of concentration ranges to higher values is limited by the solubility of lead or tin in the acid mixture, although adjustment of relative concentrations of the acids used may provide suitable conditions. 
Methods of this nature offer considerable promise in spectochemical analysis in permitting the use of standards synthesized from pure metals or salts so that calibration of the method becomes independent of other analytical methods.

The assistance of Doward M. Bouchette, Jr. in making many of the analyses is acknowledged.

\section{References}

[1] R. A. Wolfe and E. J. Jemal, Am. Soc. Testing Materials Bull. 129, 45 (1944)

[2] E. W. Palmer, J. P. Irwin, and C. C. Fogg, Am. Soc. Testing Materials Bull. 160, 41 (1949).

[3] C. Feldman, Anal. Chem. 21, 1041 (1949).

[4] B. F. Seribner and C. H. Corliss, J. Opt. Soc. Am. 33, 515 (1943)

[5] B. F. Scribner, J. Research NBS 28, 165 (1942) RP1451.

[6] H. B. Vincent and R. A. Sawyer, J. Applied Phys. 8, 163 (1937).

[7] J R. Churchill, Ind. Eng. Chem., Anal. Ed. 16, 653 (1944).

Washington, March 28, 1951 